\title{
LA INTERVENCIÓN ARMADA EN SIRIA Y EL PRINCIPIO DE LEGALIDAD
}

\author{
Paula Duro RidRuejo \\ Abogada \\ pduroridruejo@gmail.com
}

\section{INTRODUCCIÓN}

¿Estaría justificada una intervención en Siria desde el punto de vista del Derecho internacional y, concretamente, desde la perspectiva del ius ad bellum? Los conflictos a los que se refiere la Carta de Naciones Unidas son internacionales, no civiles. Pero del art. 41 del mencionado texto legal se desprende la posibilidad de intervenir de forma pacífica en conflictos internos. Entonces, ¿la intervención armada obedecería al principio de legalidad? Si nos centramos únicamente en el ius ad bellum habría que considerar las dimensiones internacionales que está tomando la guerra de Siria y su posibilidad de afectar a la paz mundial. En ese caso podría invocarse tanto el principio de autodefensa (art. 51 de la Carta de Naciones Unidas) como la teoría de la «guerra justa» para justificar la intervención. Si para responder a la pregunta anterior también tenemos en cuenta el Derecho internacional humanitario y el principio de la «Responsabilidad de Proteger», dicha intervención armada vendría impuesta por la obligación colectiva de la comunidad internacional de proteger a sus ciudadanos.

\section{EL CONFLICTO}

La guerra de Siria empezó en el contexto de la Primavera Árabe cuando en 2011 tuvieron lugar numerosas protestas en contra del presidente, Bashar al-Assad, a lo largo de todo el país. La oposición armada consistía en varios grupos formados a lo largo del conflicto. Principalmente estaba formada por el Ejército Libre Sirio (formado en 2011), el Frente Islámico 
(formado en 2013) y Hezbollah, un grupo libanés que entró en el conflicto en 2013 y apoyaba al ejército sirio.

Adicionalmente, el grupo jihadista Estado Islámico de Irak y Levante (en adelante, EI) tomó parte en las hostilidades combatiendo en contra del gobierno de Bashar al-Assad, así como contra otros grupos rebeldes. En julio de 2014, el Estado Islámico controlaba un tercio del territorio de Siria y la mayoría de su producción de petróleo y gas.

Actualmente, tras seis años de conflicto, podemos asegurar que la guerra de Siria se ha convertido en la mayor catástrofe humanitaria provocada por el ser humano desde la Segunda Guerra Mundial. A día de hoy, las estimaciones sobre el número de casualidades están en torno a las 320.000 personas, el número de desplazados internos asciende a 6,3 millones y existen aproximadamente 5 millones de refugiados.

Varias organizaciones internacionales han acusado a las fuerzas gubernamentales, al EI, así como a otros grupos rebeldes, de la comisión de graves violaciones de derechos humanos. Existen acusaciones en contra del ejército sirio por crímenes de guerra producidos principalmente por bombardear de forma deliberada ciudades y otros centros donde la mayoría de la población son civiles ${ }^{1}$. Adicionalmente, existe constancia de detenciones arbitrarias y torturas cometidas en contra de activistas en prisiones estatales ${ }^{2}$.

El Consejo de Seguridad de las Naciones Unidas (en adelante, CSNU) ha aprobado varias resoluciones condenando la violencia provocada por la guerra de Siria. Entre ellas, la Resolución $2336^{3}$, de 31 de diciembre de 2016, aprueba que se pongan en marcha los mecanismos establecidos en resoluciones anteriores, concretamente en las resoluciones $2254^{4}$ y $2268^{5}$ relativas a sentar las bases para una transición política en Siria dirigida por el propio país y al apoyo de las condiciones propuestas por Estados Unidos y la Federación Rusa para la cesación de las hostilidades un Rusia, en su declaración conjunta hecha el 22 de febrero de 2016, así como a exigir a

1 Amnistía Internacional, «Syria: "It Breaks the Human": Torture, Disease and Death in Syria's Prisons», MDE 24/4508/2016, 18 de agosto de 2016, disponible en bttps://www. amnesty.org/es/documents/mde24/4508/2016/en/.

${ }^{2}$ Ibid.

3 CSNU, S/RES/2336, Sesión 7855, de 31 de diciembre de 2016, disponible en bttp:// www.un.org/es/comun/docs/?symbol=S/RES/2336(2016).

${ }^{4}$ CSNU, S/RES/2254, Sesión 7588, de 18 de diciembre de 2015, disponible en bttp:// www.un.org/es/comun/docs/?symbol=S/RES/2254(2015).

5 CSNU, S/RES/2268, Sesión 7634, de 26 de febrero de 2016, disponible en bttp:// www.un.org/es/comun/docs/?symbol=S/RES/2268(2016). 
los Estados miembros que hagan efectivos sus compromisos tomados para ayudar al proceso de paz a través de la influencia (no militar) a los Estados parte en el conflicto.

Finalmente, existen varias denuncias por el uso de armas químicas durante el conflicto ${ }^{6}$. Muy recientemente, concretamente el 5 de abril de 2017, se ha producido el último ataque de este tipo dando como resultado la pérdida de al menos 72 vidas y 560 afectados. El ataque se produjo de madrugada en la localidad de Jan Seijun, en la provincia de Idlib, y según el Observatorio Sirio de Derechos Humanos, la autoría corresponde al ejército sirio o a la aviación rusa que lanzaron proyectiles cargados de gas serín.

La Coalición Nacional Siria ha instado al CSNU a «convocar una reunión de emergencia [...] abrir una investigación inmediata y adoptar las medidas necesarias para asegurar que los funcionarios, los perpetradores y sus respaldos rindan cuentas».

Este ataque ha provocado una gran reacción en Estados Unidos, cuyo secretario de Estado, Rex Tillerson, ha afirmado que «los sirios deben decidir el futuro de al-Assad». Por su parte, el presidente Donald Trump ha amenazado en varios medios oficiales con tomar acciones unilaterales de continuar la inactividad del CSNU ${ }^{7}$.

Dichas afirmaciones siguieron a una sesión de urgencia del $\mathrm{CSNU}^{8}$ convocada con el objetivo de tomar decisiones contundentes sobre una posible intervención en Siria. Una coalición formada por Francia, Reino Unido y Estados Unidos presentaron una propuesta de resolución en la que, si bien no se acordaban medidas sancionadoras concretas, se amenazaba a Siria con actuar.

Sin embargo, dicha propuesta no obtuvo los votos suficientes para su aprobación, como era de esperar, si tenemos en cuenta el carácter de miembro permanente que ostenta Rusia en el Consejo de Seguridad y sus intereses políticos contrapuestos a la resolución.

${ }^{6}$ B. KI-MOON, «Discurso del secretario general de Naciones Unidas sobre el Informe de la misión de la ONU para investigar las alegaciones sobre el uso de armas químicas en el incidente que ocurrió el 21 de agosto de 2013 en el área Ghouta de Damasco», 16 de septiembre de 2013, disponible en https://www.un.org/sg/en/content/sg/statement/2013-09-16/ secretary-generals-remarks-security-council-report-united-nations.

${ }^{7}$ L. M. HuRTado, «Un ataque químico mata al menos a 83 personas en Siria», El Mundo, Internacional, 7 de abril de 2017, disponible en $b t t p: / / w w w . e l m u n d o$ es/internacion al/2017/04/04/58e35091e5fdeaef34864573. html.

${ }^{8}$ CSNU, S/PV.7915, «La situación en Oriente Medio. Carta de fecha 27 de marzo de 2017 dirigida al secretario general por el presidente del Consejo de Seguridad (S/2017/260)», 5 de abril de 2017, 10:00 h, disponible en en http://www.un.org/es/comun/ docs/?symbol=S/PV.7915. 


\section{POSIBLE JUSTIFICACIÓN \\ DE UNA INTERVENCIÓN ARMADA}

\section{Desde el punto de vista del ius ad bellum}

Lo primero que debemos analizar es la justificación de una intervención en Siria desde el punto de vista del Derecho internacional y, concretamente, del ius ad bellum.

El capítulo VII de la Carta de Naciones Unidas dispone: «Acción en caso de amenazas a la paz, quebrantamiento de la paz o actos de agresión». Este capítulo concede al CSNU el poder de tomar decisiones sobre medidas ejecutivas en el caso de la existencia de amenazas contra la paz mundial.

Si leemos el mencionado capítulo en contexto, el preámbulo de la Carta y la intención del legislador en el momento de su redacción indican que con él se pretende defender el orden internacional de una posible tercera guerra mundial.

Dentro del capítulo VII, los arts. 41 y 42 tienen especial importancia.

$\mathrm{El}$ art. 41 establece que: «El Consejo de Seguridad podrá decidir qué medidas que no impliquen el uso de la fuerza armada han de emplearse para hacer efectivas sus decisiones, y podrá instar a los miembros de las Naciones Unidas a que apliquen dichas medidas, que podrán comprender la interrupción total o parcial de las relaciones económicas y de las comunicaciones ferroviarias, marítimas, aéreas, postales, telegráficas, radioeléctricas y otros medios de comunicación, así como la ruptura de relaciones diplomáticas».

De la lectura de este artículo se desprende que el mismo se refiere indistintamente a guerras internacionales y a guerras civiles. Sin embargo, el art. 42, que permite el uso de la fuerza, dice explícitamente que su propósito es «mantener o restablecer la paz y la seguridad internacionales». Por tanto, el problema es si una guerra civil puede ser considerada como una amenaza a la paz y la seguridad internacional.

Tomando como ejemplo la Primera Guerra del Golfo, cuando los aliados intervinieron Irak, los kurdos querían que la coalición anti-Irak les liberara, junto con Kuwait, del gobierno de Saddam Hussein. Sin embargo, dicha demanda pronto suscitó dudas acerca de la legalidad de intervenir Irak para ayudar a un movimiento secesionista. A pesar de haber una justificación humanitaria para la intervención, porque se estaban produciendo violaciones masivas de derechos humanos (como es el caso de Siria 
hoy), el art. 42 de la Carta de Naciones Unidas no autoriza al Consejo de Seguridad a emitir resoluciones que permitan el uso de la fuerza?.

De hecho, la doctrina internacional —Carl-August Fleischauer, entre otros autores- coincidió en que la Resolución 678 de la ONU autorizando el uso de la fuerza en contra de Irak no se adoptó bajo la autoridad del art. 42, sino que fue simplemente el ejercicio del poder del Consejo de Seguridad conforme al capítulo VII.

Derivado de las conclusiones anteriores cabe preguntarse si el capítulo VII de la Carta de Naciones Unidas autoriza la intervención armada en una guerra civil si ésta presenta un carácter internacional.

No sería difícil defender la tesis de que la guerra de Siria se ha convertido en una guerra internacional o, por lo menos, que sus efectos transcienden sus fronteras. Los principales aliados del gobierno sirio son Irán y Hezbollah (y Rusia). Por otro lado, la coalición siria recibe ayuda política, logística y militar de Estados Unidos, Gran Bretaña y Francia, así como de otros Estados de mayoría suní como Turquía, Qatar y Arabia Saudí. Finalmente, el Estado Islámico, con más de 3.000 yihadistas provenientes de fuera de Siria, supuestamente cuenta con donaciones privadas procedentes de los países del golfo.

Además, no sólo el conflicto en sí mismo, sino también sus consecuencias humanitarias tienen una dimensión supranacional. La guerra de Siria es la causa principal de la crisis de refugiados que está viviendo Europa. Dicha crisis ha sido preponderante en el germen de la inestabilidad política y económica que vive la Unión Europea en estos momentos, del auge de los extremismos y las ideas proteccionistas, de los atentados terroristas y de los sentimientos de xenofobia.

En este contexto, los principios de autodeterminación de los pueblos y de no intervención en los asuntos internos de los Estados garantizados en el art. 2.7 de la Carta de Naciones Unidas se perciben de manera más débil, y la necesidad de mantener la paz y la seguridad mundiales (capítulo VII) parece latente.

En este punto, dado que la guerra de Siria se percibe como una amenaza a la paz mundial, cla comunidad internacional podría justificar una intervención armada como autodefensa?

El art. 51 de la Carta de Naciones Unidas establece que la autodefensa es la única excepción existente frente a la obligación del art. 39, que impo-

9 ONU, Repertorio de la práctica del Consejo de Seguridad, suplemento 1989-1992, pp. 695-698, disponible en bttp://www.un.org/es/sc/repertoire/89_92/89-92_11.pdf\#page=29. 
ne la existencia de una recomendación o medida del CSNU como requisito previo a una intervención en otro país. Aquel artículo estipula: «Ninguna disposición de esta Carta menoscabará el derecho inmanente de legítima defensa, individual o colectiva, en caso de ataque armado contra un miembro de las Naciones Unidas, hasta tanto que el Consejo de Seguridad haya tomado las medidas necesarias para mantener la paz y la seguridad internacionales. Las medidas tomadas por los miembros en ejercicio del Derecho de legítima defensa serán comunicadas inmediatamente al Consejo de Seguridad y no afectarán en manera alguna la autoridad y responsabilidad del Consejo conforme a la presente Carta para ejercer en cualquier momento la acción que estime necesaria con el fin de mantener o restablecer la paz y la seguridad internacionales».

Es decir, desde esta perspectiva, la comunidad internacional podría intervenir en Siria para poner fin al conflicto armado como prevención a la amenaza de un conflicto internacional mayor.

Para finalizar el análisis desde el punto de vista del ius ad bellum, es importante tomar en cuenta consideraciones de la teoría de la guerra justa. Es decir, una intervención armada de la comunidad internacional en Siria debería estar justificada bajo la perspectiva de esta teoría.

Existen discrepancias acerca del significado de guerra justa. Sin embargo, parece claro que este término nació de las consideraciones morales sobre el ius ad bellum en el siglo XI. Cicerón fue el fundador del análisis sistemático de la guerra justa. Para él eran justas causas para una guerra la rehabilitación y la disuasión. Por su parte, la tradición cristiana ${ }^{10}$ partía de una concepción pacifista basada en la idea de San Agustín de que la paz del universo es la tranquilidad del orden (tranquillitas ordinis). Bajo esta idea, la consecución de la paz mundial era un objetivo prioritario al principio de no-intervención.

Posteriormente, Michael Walzer definió una idea de guerra justa que tuvo gran acogida. Partía de la idea de una moral común que está en la base de la doctrina de los derechos humanos. Toma una posición legalista moderna que considera que el uso de la fuerza sólo está justificado en defensa propia para evitar y para penar la agresión. Según el citado autor, «cualquier Estado capaz de parar la sangre tiene el derecho, al menos, de intentarlo», e incluso deja abierta la posibilidad de un cambio de régimen

${ }^{10}$ San Agustín, Santo Tomás de Aquino, Victoria y Suárez, Gentili y Grotius, entre otros. Vid. R. H. Bainton, Christian Attitudes toward War and Peace: A Historical Survey and Critical Re-evaluation, New York, Abingdon Press, 1960. 
como el límite externo de las causas justas por las que estaría justificado el uso de la fuerza.

John Rawls, por su parte, afirma que el Derecho internacional es incompleto. Carece de un sistema efectivo de sanciones. Rawls identifica el contenido mínimo del ius gentium con la universalidad de los derechos humanos básicos. Por tanto, este autor rechaza la idea de un «bien común». Según él, cada Estado tiene el poder de actuar conforme a su propia idea de bien común. No obstante, el límite está en la defensa de dichos derechos humanos básicos, como el derecho a la vida, a la dignidad, a la integridad física y moral, y a la libertad, entre otros ${ }^{11}$.

Así, sin ánimo de exhaustividad, las razones que podrían justificar una intervención internacional en Siria son: prevenir el uso de armas químicas, prevenir o condenar los crímenes cometidos, contraterrorismo (ISIS), poner fin a la crisis de refugiados, proteger a la población civil, estabilizar la región, reconstruir el país o provocar un cambio de régimen, entre otros.

Ante este panorama se han suscitado varios debates en el seno de la ONU sobre la posibilidad de limitar el poder de veto de los miembros permanentes del Consejo de Seguridad cuando existen crímenes internacionales - léase crímenes de guerra, crímenes de lesa humanidad, genocidio y agresiones- que están provocando consecuencias humanitarias irreparables ${ }^{12}$.

Sin embargo, mientras la anterior idea no se materialice es necesario tener en cuenta otras justificaciones, diferentes a las meramente legalistas, para evitar mirar para otro lado en crisis como la de Siria que se ha cobrado cientos de miles de vidas humanas.

11 T. Pangle y P. Ahrensdorf, Justice Among Nations: On the Moral Basis of Power and Peace, Kansas, University Press of Kansas, 1999, pp. 51-72; W. GreWe, The Epochs of International Law, traducción de M. Byers, Berlin-New York, Walter de Gruyter, 2000, pp. 279-342 (describe la era del «balance de poderes»), e I. Kant, Perpetual Peace, reimp. en G. M. Reichberg, H. Syse y E. Begby (eds.), The Ethics of War: Classic and Contemporary Readings, Malden-Oxford, Blackwell Publishing, 2006, pp. 422, 520-521 y 620.

12 E. MenéndeZ del Valle, «El derecho de veto en el Consejo de Seguridad de Naciones Unidas: ¿obstáculo insalvable para la Responsabilidad de Proteger?», Real Instituto El Cano, documento de trabajo 15/2016, 27 de diciembre de 2016, disponible en bttp://www.realins titutoelcano.org/wps/wcm/connect/1f36d85f-ce7f-4c09-8cbe-a744fb1c656d/DT14-2016-Menen dezdelValle-Derecho-veto-Consejo-Seguridad-Naciones-Unidas-Responsabilidad-de-Proteger.pdf ?MOD=AJPERESEcacheid $=1482831227967$. 


\section{Desde una perspectiva humanitaria}

Como dijo Barak Obama en su discurso de la ceremonia del Premio Nobel de la Paz el 10 de diciembre de 2009, «si atendemos a las ideas clásicas del ius gentium provenientes del ius natural, la protección de los derechos humanos debería ser una consideración prioritaria para el ius ad bellum».

El Protocolo de Ginebra de 1925 relativo a la prohibición en la guerra del empleo de gases asfixiantes, tóxicos o similares y de medios bacteriológicos (firmado por Siria) prohíbe el uso de armas químicas o biológicas en guerra contra otros Estados. Sin embargo, no contiene referencias a las guerras civiles.

Por otro lado, dado que Siria no es miembro de la Convención sobre las Armas Químicas, la Organización para la Prohibición del Uso de Armas Químicas no puede exigir un desarme inmediato en el país. Por ello, el CSNU debería promover un mecanismo de desarme alternativo como hizo en Irak en 1991 (Resolución 687).

Pero el argumento más importante para justificar una intervención armada en Siria desde una perspectiva humanitaria es el principio internacional de Responsabilidad de Proteger (en adelante, R2P). Este concepto apareció por primera vez en el Informe de la Comisión Internacional sobre la Intervención y la Soberanía de los Estados de diciembre de $2001^{13}$. Su objetivo era, y continúa siendo, la reconciliación entre el concepto tradicional de soberanía — que supone el control exclusivo y la supremacía sobre un territorio determinado- y la noción moderna de soberanía - que establece que la principal responsabilidad de un Estado es la de proteger a sus ciudadanos-.

Esta comisión creyó que la posición de la Carta de Naciones Unidas en contra de la intervención armada no puede ser vista como absoluta cuando - como es el caso de Siria- es necesario tomar acciones decisivas para proteger vidas humanas. Este argumento aparece reforzado por una gran variedad de fuentes legales. Así, los principios fundamentales del Derecho natural, las provisiones de derechos humanos de la Carta de Naciones Unidas, la Declaración Universal de Derechos Humanos, la Convención en contra del Genocidio, las Convenciones de Ginebra de

13 ICISS, «La Responsabilidad de Proteger», diciembre de 2001, disponible en bttp:// www.ceipaz.org/images/contenido/La\%20responsabilidad\%20de\%20proteger_ESP.pdf. 
Derecho internacional humanitario y sus protocolos adicionales, y el Estatuto de Roma.

El informe sobre la Responsabilidad de Proteger se centra en el concepto de sociedad civil transnacional cuando dice que el Consejo de Seguridad, pero también «los miembros de la amplia comunidad de Estados», tiene una responsabilidad de proteger no sólo a sus propios ciudadanos, sino también a aquellos ciudadanos de otros Estados.

Algunas de las conclusiones de este informe afectaron de manera directa el documento final de la Cumbre Mundial de 2005, que elaboró la Asamblea General de Naciones Unidas (en adelante, AGNU) con ocasión de su 50 aniversario. En este sentido, la AGNU aceptó la legalidad de la autoridad del capítulo VII de la Carta de Naciones Unidas en conflictos domésticos ${ }^{14}$ en los que tienen lugar serias violaciones de derechos humanos.

Asimismo, la AGNU dio su respuesta respecto a esta cuestión en el Documento Final de la Cumbre Mundial de 2005: «Cada Estado tiene la responsabilidad de proteger a su población del genocidio, de los crímenes de guerra, de la limpieza étnica y de los crímenes de lesa humanidad. La comunidad internacional debe, según proceda, incentivar y ayudar a los Estados a ejercer esta responsabilidad y apoyar a las Naciones Unidas en el establecimiento de una alerta temprana» ${ }^{15}$.

En resumen, la Cumbre Mundial de 2005 sirvió para que la Asamblea General reconociera: 1) que la soberanía de los Estados bajo el art. 2(7) de la Carta de Naciones Unidas tiene límites y que el trato que un Estado da a su población es una cuestión de preocupación internacional, y 2) que la Responsabilidad de Proteger es una norma política con un gran contenido moral, susceptible de convertirse en una norma de ius cogens vinculante jurídicamente.

La jurisprudencia de la Corte Internacional de Justicia (en adelante, CIJ) avala la doctrina de la R2P. En su sentencia sobre el caso Bosnia c. Serbia de 26 de febrero de 2007, relativa a genocidio, la Corte afirmó que la obligación de los Estados de prevenir el genocidio consiste en emplear todos los medios razonablemente disponibles para tal fin. El alto tribunal aclaró que se trata de una obligación de medios y no de resultado. En este

${ }^{14}$ Civiles o que se desarrollan dentro del territorio de un estado.

15 AGNU, «Draft resolution referred to the High-level Plenary Meeting of the General Assembly by the General Assembly at its fifty-ninth session», A/60/L.1, sesión 60, 15 de septiembre de 2005, disponible en bttp://responsibilitytoprotect.org/world\%20summit $\% 20$ outcome\%20doc\%202005(1).pdf. 
sentido, dice la sentencia, el concepto de «diligencia debida», que debe ser valorado en cada caso concreto, cobra especial importancia.

Según la CIJ, uno de los parámetros para medir si un Estado está empleando toda la diligencia que le exige el principio de R2P es la capacidad de influencia sobre las personas que están cometiendo o son susceptibles de cometer el crímen (de genocidio, en este caso). A este respecto, la CIJ argumenta que es irrelevante que el país cuya responsabilidad se analiza alegue o incluso pruebe que, aunque hubiera utilizado todos los medios a su alcance, no habría conseguido prevenir o terminar con el genocidio. $\mathrm{La}$ R2P es una responsabilidad del conjunto de la comunidad internacional y existe la posibilidad de que, a través del esfuerzo conjunto de varios Estados, cada uno de ellos en respuesta a su obligación individualmente considerada, se consiga el objetivo perseguido ${ }^{16}$.

En el caso de Siria, además del argumento - ampliamente compartido- de que la responsabilidad de proteger es una obligación de la comunidad internacional en su conjunto, podemos apoyarnos en el precedente de la guerra de Kosovo para afirmar la legalidad de una intervención armada.

La mayor parte de la doctrina internacional considera que la Resolución $1244^{17}$, dictada después de la intervención armada de la OTAN en Yugoslavia en 1999, supuso una ratificación retroactiva a dicha intervención. Ésta es la primera vez en que la comunidad internacional intervino en un conflicto armado interno para proteger a la población civil de las masivas violaciones de derechos humanos que se estaban cometiendo sin una previa resolución del Consejo de Seguridad de las Naciones Unidas autorizándolo.

Por tanto, tomando como punto de partida la anterior resolución y apoyando nuestro argumento en la obligación generalizada de la R2P, una intervención actual en Siria estaría avalada legalmente aunque algunos miembros del Consejo de Seguridad de Naciones Unidas vetaran una resolución previa a tal efecto.

Éste es el punto de vista del secretario general Ban ki-Moon, quien dijo en el Asamblea General de la ONU de 2009 que «el secretario general tiene la obligación de decir al Consejo de Seguridad lo que tiene que saber, no lo que quiere escuchar. El secretario general debe erigirse en por-

${ }^{16}$ ICJ, Judgment of Feb. 26, 2007, Case Concerning Genocide (Bosnia v. Serbia), párr. 430.

${ }_{17}$ CSNU, S/RES/1244, de 10 de junio de 1999, disponible en http://www.defensa.gob. es/Galerias/areasTematicas/misiones/fichero/resolucion-ONU-1244.pdf. 
tavoz de los vulnerables y los amenazados cuando sus gobiernos se convierten en perseguidores en lugar de protectores o cuando ya no pueden protegerlos de grupos armados dedicados al saqueo. Los cinco miembros permanentes del Consejo de Seguridad tienen una responsabilidad especial debido a los privilegios de titularidad y derecho de veto que les han sido concedidos en la Carta. Les instaría a abstenerse de ejercer o amenazar con ejercer su derecho de veto en situaciones en que sea evidente que no se han cumplido obligaciones relativas a la Responsabilidad de Proteger [...] En todo el planeta se ha experimentado un cambio de actitud considerable desde lo sucedido en Camboya, Ruanda y Srebrenica, y aumentado el precio político, tanto a nivel nacional como internacional, que deben pagar quienes parezcan estar bloqueando una acción internacional eficaz mientras se comete un genocidio u otro crimen relativo a la Responsabilidad de Proteger [...] Para que la Asamblea General pueda desempeñar un papel rector al configurar la acción de las Naciones Unidas, los 192 Estados miembros tienen la obligación común de convertirla en un instrumento eficaz para promover los principios de la Responsabilidad de Proteger que tan claramente se enuncian en los párrafos 138 y 139 del Documento Final de la Cumbre» ${ }^{18}$.

Una vez aclarado que el principio de Responsabilidad de Proteger podría justificar una intervención en Siria, es importante analizar si se cumplen los requisitos que el Informe de ICISS (referido ut supra) establece a tal efecto:

1. En primer lugar, se requiere la existencia de una causa justa. Es decir, el conflicto debe tener o ser susceptible de que se produzcan consecuencias humanitarias graves derivadas de crímenes de guerra, de lesa humanidad o de genocidio. Por tanto, dichos crímenes deben revestir cierta entidad. Según el ICISS, uno de los rasgos fundamentales de los mismos es su comisión dentro de una política del Estado u otro grupo organizado. Este requisito exige que exista una necesidad militar para la intervención. $\mathrm{El}$ art. 52.2 del Protocolo I Adicional a las Convenciones de Ginebra (en adelante, PA I) ${ }^{19}$ es un ejemplo moderno de cómo el requisito de la necesidad militar puede actuar como un límite a la intervención. Dicho precepto

${ }_{18}$ Naciones Unidas, Asamblea General, «Hacer efectiva la Responsabilidad de Proteger», A/63/677, 12 de enero de 2009, párr. 61.

19 AGNU, «Protocolo I adicional a los Convenios de Ginebra de 1949 relativo a la protección de las víctimas de los conflictos armados internacionales», de 8 de junio de 1977, art. 52.2, disponible en https://www.icrc.org/es/guerra-y-derecho/ tratados-de-dib-y-el-dib-consuetudinario/convenios-de-ginebra. 
dispone: «Los ataques se limitarán estrictamente a los objetivos militares. En lo que respecta a los bienes, los objetivos militares se limitarán a aquellos objetos que por su naturaleza, ubicación, finalidad o utilización contribuyan eficazmente a la acción militar o cuya destrucción total o parcial, captura o neutralización, ofrezca en las circunstancias del caso una ventaja militar definida».

Otro precepto que avala la «necesidad militar» como excepción al principio de autodeterminación de los pueblos y de no intervención en los asuntos internos de los Estados se encuentra en el art. 53 del Cuarto Convenio de Ginebra de 1949, relativo a la protección debida a las personas civiles en tiempo de guerra, que prohíbe a los beligerantes destruir la propiedad protegida «excepto en los casos en que tales destrucciones sean absolutamente necesarias a causa de las operaciones bélicas».

La posición de la Corte Internacional de Justicia (en adelante, CIJ) a este respecto se encuentra en su sentencia del caso de «the hostages» ${ }^{20}$. En ella, la CIJ sanciona las medidas tomadas por Irán, necesarias para mantener la seguridad de sus fuerzas armadas y para garantizar el éxito de sus operaciones, porque, según la opinión de la CIJ, la destrucción de vidas de enemigos armados, así como la de otras personas que sean inevitables, sólo está justificada en la medida en que lo permita la ley de la guerra.

2. En segundo lugar, es necesario que el objetivo de la intervención sea la protección de los derechos humanos. Para ello se exige que la intervención sea colectiva. De hecho, es deseable conseguir el mayor número de apoyos posible dentro de la comunidad internacional, sobre todo entre los Estados próximos al conflicto y la propia población civil que se intenta proteger.

Este requisito está íntimamente relacionado con el principio de distinción o de inmunidad civil en un conflicto armado. Es decir, el Derecho internacional es claro al asegurar que la población civil no puede ser el objetivo de ningún ataque militar ${ }^{21}$. De hecho, esta prohibición no puede ser derogada a través de la invocación de la existencia de «necesidad militar».

Adicionalmente, el art. 48 del Protocolo Adicional I a las Convenciones de Ginebra de 1948, rubricado de la norma fundamental y del ámbito de aplicación del convenio, establece que: «A fin de garantizar el res-

${ }^{20}$ CIJ, Estados Unidos de América c. Irán, Sentencia de 24 de junio de 1980, disponible

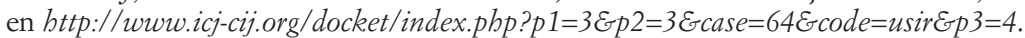

${ }^{21}$ AGNU, Protocolo I adicional a los Convenios de Ginebra de 1949, art. 51.2. 
peto y la protección de la población civil y de los bienes de carácter civil, las partes en conflicto harán distinción en todo momento entre población civil y combatientes, y entre bienes de carácter civil y objetivos militares, $y$, en consecuencia, dirigirán sus operaciones únicamente contra objetivos militares».

3. En tercer lugar, es un requisito indispensable que la intervención debe ser el último recurso. Es decir, se debe cumplir con el principio de subsidiariedad que rige el Derecho internacional. Para justificar el uso de la fuerza, los que la aleguen deben demostrar haber agotado todas las vías pacíficas de solución del conflicto. Estas vías se concretan en soluciones diplomáticas en la mayoría de los casos. Es discutible, sin embargo, si es suficiente con la existencia de motivos razonables para creer que, aun cuando se hubiese intentado la solución por un medio pacífico, la misma no habría tenido efecto.

4. En cuarto lugar, se requiere que los medios utilizados sean proporcionales a los fines que se pretenden conseguir. Para analizar el cumplimiento con el estándar de proporcionalidad hay que atender a la escala, la intensidad y la duración de la intervención planificada, que deben ser las mínimas posibles para asegurar el objetivo humanitario en cuestión ${ }^{22}$.

La exigencia de proporcionalidad puede ser descrita como un balance entre la «necesidad militar» y «la humanidad» de la intervención. Aunque no contengan expresamente el término «proporcionalidad», los arts. 51 y 57 del PA I incluyen la afirmación más autoritaria al principio de proporcionalidad del ius in bello contemporáneo. El art. 51.4 prohíbe todos los ataques «indiscriminados» y el art. 51.5 proporciona una lista no exhaustiva de ataques prohibidos incluyendo, inter alia: «b) los ataques, cuando sea de prever que causarán incidentalmente muertos y heridos entre la población civil, o daños a bienes de carácter civil, o ambas cosas, que serían excesivos en relación con la ventaja militar concreta y directa prevista». Por su parte, los arts. 57.2.a).iii) y 57.2.b) proporcionan un contenido similar.

5. En quinto lugar, es un requisito muy debatido y con gran importancia en la práctica el hecho de que existan posibilidades de éxito razonables ${ }^{23}$. Este requisito implica que si no se puede, o es muy remota la

${ }^{22}$ ICISS, «La Responsabilidad de Proteger», op. cit.

${ }^{23}$ Requisito establecido, a parte de por el ICISS, por el secretario general de la ONU, K. Annan, «In Larger Freedom: Towards Development, Security and Human Rights for All», Informe A/59/2005, disponible en http://www.un.org/en/ga/search/view_doc. asp? symbol $=A / 59 / 2005$. 
posibilidad de prevenir o remediar las violaciones de derechos humanos que se están cometiendo, o si el coste de la intervención, en términos humanitarios, es superior a sus beneficios, es muy probable que la intervención cause más daño que la no-intervención. Por tanto, es preferible la segunda.

Las cuestiones más frecuentes en relación a este último requisito se centran en la posibilidad de que, a raíz de una intervención con fines humanitarios, se desencadene un conflicto mayor. Esto es posible si la intervención no se realiza por un número elevado de países, o si éstos no cuentan con el apoyo de las principales potencias mundiales ${ }^{24}$.

\section{CONCLUSIONES}

Llegados a este punto se podría concluir que si bien el Derecho internacional público no permite expresamente una intervención armada en Siria, ésta se podría justificar por causas humanitarias. A pesar de que el art. 39 de la Carta de Naciones Unidas exige una resolución previa del Consejo de Seguridad, ésta admite excepciones — prueba de ello es el art. 51 relativo a la autodefensa-, y la comisión de crímenes internacionales de guerra, de lesa humanidad y de genocidio con total impunidad es —o debería ser- una de ellas.

Con el nacimiento del principio de «Responsabilidad de Proteger» parece que la comunidad internacional ha avanzado hacia una protección más garante de los derechos humanos de los ciudadanos generalmente considerados. Sin embargo, en el caso de Siria parece que han prevalecido otro tipo de intereses que los meramente humanitarios.

\section{BIBLIOGRAFÍA}

AGNU, «Protocolo I adicional a los Convenios de Ginebra de 1949 relativo a la protección de las víctimas de los conflictos armados internacionales», 8 de junio de 1977, arts. 51.2-52.2, disponible en bttps://www.icrc.org/es/ guerra-y-derecho/tratados-de-dih-y-el-dih-consuetudinario/convenios-de-ginebra.

${ }^{24}$ T. Pande Braathen, «The Responsibility to Protect and the Importance of International Consensus», E-International Relations Students, 8 de julio de 2015, disponible en http://www.e-ir.info/2015/07/08/the-responsibility-to-protect-and-the -importance-of-international-consensus/. 
- «Draft resolution referred to the High-level Plenary Meeting of the General Assembly by the General Assembly at its fifty-ninth session», A/60/L.1, sesión 60, 15 de septiembre de 2005, disponible en bttp://responsibilitytoprotect.org/world\%20summit\%20outcome\%20doc\%202005(1).pdf

- «Hacer efectiva la Responsabilidad de Proteger», A/63/677, 12 de enero de 2009, párrafo 61 .

Amnistía Internacional, «Syria: "It Breaks the Human": Torture, Disease and Death in Syria's Prisons», MDE 24/4508/2016, 18 de agosto de 2016, disponible en https://www.amnesty.org/es/documents/mde24/4508/2016/en/.

Annan, K., «In Larger Freedom: Towards Development, Security and Human Rights for All», Informe A/59/2005, disponible en bttp://www.un.org/en/ga/ search/view_doc.asp?symbol=A/59/2005.

Bainton, R. H., Christian Attitudes toward War and Peace: A Historical Survey and Critical Re-evaluation, New York, Abingdon Press, 1960.

CIJ, Estados Unidos de América c. Irán, Sentencia, 24 de junio de 1980, disponible en http://www.icj-cij.org/docket $/$ index.php? $p 1=3 \varepsilon p 2=3 \varepsilon$ case $=64 \varepsilon$ code $=u$ sir $\varepsilon p 3=4$.

CSNU, S/RES/1244, de 10 de junio de 1999, disponible en bttp://www.defensa.gob.es/Galerias/areasTematicas/misiones/fichero/resolucion-ONU-1244.pdf.

- S/RES/2254, Sesión 7588, de 18 de diciembre de 2015, disponible en bttp:// www.un.org/es/comun/docs/?symbol=S/RES/2254(2015).

— S/RES/2268, Sesión 7634, de 26 de febrero de 2016, disponible en http:// www.un.org/es/comun/docs/?symbol=S/RES/2268(2016).

— S/RES/2336, Sesión 7855, de 31 de diciembre de 2016, disponible en bttp:// www.un.org/es/comun/docs/?symbol=S/RES/2336(2016).

- S/PV.7915, «La situación en oriente Medio. Carta de fecha 27 de marzo de 2017 dirigida al secretario general por el presidente del Consejo de Seguridad (S/2017/260)», 5 de abril de 2017, 10:00 h, disponible en bttp://www.un.org/ es/comun/docs/?symbol=S/PV.7915.

GREWE, W., The Epochs of International Law, traducción de M. Byers, Berlin-New York, Walter de Gruyter, 2000.

Hurtado, L. M., «Un ataque químico mata al menos a 83 personas en Siria», El Mundo, Internacional, 7 de abril de 2017, disponible en bttp://www.elmundo. es/internacional/2017/04/04/58e35091e5fdeaef34864573. html.

ICISS, «La Responsabilidad de Proteger», diciembre de 2001, disponible en http:// www.ceipaz.org/images/contenido/La\%20responsabilidad\%20de\%20proteger_ ESP.pdf.

ICJ, Judgment of Feb. 26, 2007, Case Concerning Genocide (Bosnia v. Serbia), párr. 430.

Kant, I., Perpetual Peace, reimp. en G. M. Reichberg, H. Syse y E. Begby (eds.), The Ethics of War: Classic and Contemporary Readings, Malden-Oxford, Blackwell Publishing, 2006, pp. 422, 520-521 y 620. 
Ki-MOON, B., «Discurso del secretario general de Naciones Unidas sobre el Informe de la misión de la ONU para investigar las alegaciones sobre el uso de armas químicas en el incidente que ocurrió el 21 de agosto de 2013 en el área Ghouta de Damasco», 16 de septiembre de 2013, disponible en https://www.un.org/sg/en/content/sg/statement/2013-09-16/ secretary-generals-remarks-security-council-report-united-nations.

Menéndez Del Valle, E., «El derecho de veto en el Consejo de Seguridad de Naciones Unidas: ¿obstáculo insalvable para la Responsabilidad de Proteger?», Real Instituto El Cano, documento de trabajo 15/2016, 27 de diciembre de 2016, disponible en http://www.realinstitutoelcano.org/wps/wcm/ connect/1f36d85f-ce7f-4c09-8cbe-a744fb1c656d/DT14-2016-MenendezdelValleDerecho-veto-Consejo-Seguridad-Naciones-Unidas-Responsabilidad-de-Proteger. pdf?MOD=AJPERESEcacheid $=1482831227967$.

ONU, Repertorio de la práctica del Consejo de Seguridad, suplemento 1989-1992, pp.695-698, disponible en bttp://www.un.org/es/sc/repertoire/89_92/89-92_11. pdf\#page $=29$.

Pangle, T., y Ahrensdorf, P., Justice Among Nations: On the Moral Basis of Power and Peace, Kansas, University Press of Kansas, 1999.

Pande Braathen, T., «The Responsibility to Protect and the Importance of International Consensus», E-International Relations Students, 8 de julio de 2015, disponible en http://www.e-ir.info/2015/07/08/ the-responsibility-to-protect-and-the-importance-of-international-consensus/. 